\title{
Pathological and clinical findings in a series of 22 cases of medullary carcinoma of the thyroidat the korle-bu teaching hospital (1994-2013)
}

Edmund Muonir Der ${ }^{1,2}$

Correspondence: maadelle@yahoo.com

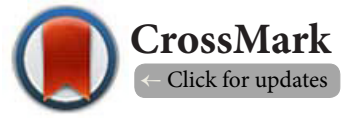

'Department of Pathology Korle-Bu Teaching hospital, PO Box 77, Korle-Bu, Accra-Ghana.

${ }^{2}$ Department of Pathology University for Development Studies, Tamale PO Box 77, 183, Tamale -Ghana.

\begin{abstract}
There is paucity of published data on medullary thyroid cancer (MTC) as a single entity in Ghana and Africa as a whole despite its first description six decades ago. The aim of this study was to determine the proportions of thyroid malignancies diagnosed in the department of pathology of the Korle-Bu Teaching Hospital (KBTH) between 1994-2013 that were MTCs and the clinicopathological characteristics by a retrospective histopathological study.

Material and methods: This was a retrospective study in KBTH from 1994 to 2013.

Results: During the period under review, MTC was found to be the third common thyroid malignancy, accounting for $10.0 \%$ of all the cases. The mean age of patient was 38.4 years ( $\mathrm{SD} \pm 16.0)$ with half (50.0\%) being younger than 40 years of age. The male to female ratio was 1:1. The modal age of the males was $40-49$ years (27.3\%), but that for the females was 20-29 years (36.4\%). Anterior neck swelling was the commonest presentation of MTCs (95.5\%), particularly diffuse gland involvement (45.5\%). Males with MTC presented relatively early within two years $(50.0 \%)$, compared to females who commonly presented after 5 years $(37.5 \%)$ with the disease. AMTCs were commonly diagnosed in lobectomy specimens (44.4\%). Two of the females had neck dissection (18.2\%). Extra-glandular spread at diagnosis was found in lymph nodes (22.7\%), lymphovascular space (13.6\%) and neck muscles (13.6\%).

Conclusion: Medullary thyroid cancer was found to be the third common thyroid malignancy at KBTH with no significant sex differences in the clinical presentation. Patients commonly presented with large anterior neck swelling of variable duration. Approximately $59.1 \%$ of the patients had organ confirmed disease at diagnosis.
\end{abstract}

Keywords: Medullary thyroid cancer, neuroendocrine, Ghana, extra-glandular spread, anterior neck swelling

\section{Introduction}

Medullary thyroid cancer (MTC) is a neuroendocrine carcinoma, composed of malignant C-cells (parafollicular cells) [1]. MTC was first described by Hazard et al., in 1959 [2]. The majority of MTCs are sporadic, but approximately $20 \%$ of MTCs are as a result of a germline genetic mutation in the rearranged during transfection (ret) proto-oncogene. Hereditary MTC can be seen in isolation (familial medullary thyroid cancer [FMTC]) or as part of the multiple endocrine neoplasia (MEN) syndrome type 2 (2A or 2B) [3-6]. The associations of MTC and neuroendocrine disorders was described by Steiner and colleagues in 1968 [7].

The relative proportion of MTC among thyroid malignancies varies across Africa [8-11] and globally [12-14]. For instance Sippel et al., in their study found that MTC accounts for approximately $10.0 \%$ of all thyroid malignancies [12], while Well et al., found 1-2\% [14].

The age at diagnosiswith MTC varies among studies $[15,16]$. MTC may show slight female preponderance $[12,13]$, one study found male preponderance [17], while Grubbs et al., [18] found no sex differences. The commonest clinical presentation of MTC 
Edmund Muonir Der, Pathology Discovery 2017,

from previous studies is an enlarged thyroid gland, especially at the poles $[19,20]$.

The prognosis of MTC is worsened by advanced age ( $>65$ years) at diagnosis, in patients diagnosed with the sporadic variant, cases with paucity of calcitonin immunostaining and rising serum carcinoembryonic antigen (CEA) level [21-26].

Medullary thyroid cancer has generally not been studied as a single entity in Africa, West Africa including Ghana Similarly the relative proportion of thyroid malignancies that are MTCs and the clinical presentation have not being studied in Ghana. The aim of this study was to determine the proportions of histologically diagnosed thyroid malignancies and the associated clinicopathological characteristics from 1994-2013, in the department of pathology of the KBTH, by a retrospective histopathological study.

\section{Materials and methods Study design}

This was a retrospective review from January 1994 to December 2013.

\section{Study site}

The study was conducted in the Department of Pathology, Korle-Bu Teaching Hospital (KBTH) the biggest referral hospital in Ghana. Surgical specimens are received from the Korle-Bu teaching hospital and other hospitals across the region and beyond.

\section{Data collection and analysis}

All clinical request forms, the histology reports and the corresponding histology slides of all thyroid malignancies diagnosed in the department institution from January 1994 to December 2013 were reviewed. Data were collected on the demographic features and the histopathological characteristics of MTCs diagnosed during the period of underreview. Data were entered into and analysed using SPSS software version 23.0 (Chicago).

The total number of thyroid malignancies diagnosed over the period of study was determined over the period 1994-2013.

The relative proportions of the subtypes of the TMs were determined: Papillary, follicular, anaplastic, medullary, and others were determined over the period 1994-2013.

The clinicopathological characteristics of patients diagnosed with MTCs including the types of surgical specimens were then determined separately as an entity.

Descriptive statistics of mean and standard deviation were used to describe the data. The results were presented in frequency tables and a histogram. The clinical presentations of MTC in males and females were compared using Chi-Square Test.

\section{Availability of data}

The data used to prepare this manuscript will be made available on demand.

\section{Inclusion criteria}

All histologically confirmed thyroid malignancies were included.

\section{Exclusion criteria}

All cases of poorly fixed specimens and those with incomplete records were excluded from the analysis.

\section{Results}

Age characteristics of patients diagnosed with MTC During the period under review, a total of 220 thyroid malignancies were diagnosed. Of this number, 22 (10.0\%) were MTCs, thus making it the third common TM, after papillary (52.7\%) and follicular (35.0\%) respectively. The ages of patients diagnosed with MTC range from 11 to 73 years with a mean age of 38.4 years (SD \pm 16.0 ) and a modal age group of 40-49 years. There were equal numbers of males and females patients respectively. Approximately half $(50.0 \%)$ of the patients were younger than 40 years. There were no significant age differences between males and females ( $p$-value $=0.530$ ), (Tables 1 and 3).

\section{Clinical presentation and laterality of symptoms}

All the patients diagnosed of MTCs presented with neck swelling, of which 21 (95.5\%) involved the thyroid gland. Only one patient presented with cervical lymphadenopathy (4.5\%). Of those with thyroid gland enlargement, $45.5 \%$ presented with diffuse gland enlargement (Table 2).

\section{Duration of symptoms at presentation of MTC}

A total of $16(72.7 \%)$ of the patients had stated duration of the symptoms at presentation ( 8 males and 8 females). Approximately half (50.0\%) of the males presented within two years of noticing the swelling while $37.5 \%$ of females presented at 5 or more yearsof onset of the disease. There were no significant differences in duration at presentation between males and females (Tables 2 and 3 ).

Types of surgical specimens in which MTC was diagnosed A total of 11 (44.4\%) patients with MTCs were diagnosed in lobectomies. Majority of males had lobectomy $(54.5 \%)$ compared to $45.4 \%$ of females (Table 2). Two of the female patients

Table 1. Age groups of male and female patients diagnosed with MTC.

\begin{tabular}{llll}
\hline & Whole group & Male & Female \\
\hline Age group (years) & $(\mathbf{n} / \%)$ & $(\mathbf{n} / \%)$ & $(\mathbf{n} / \%)$ \\
\hline$\leq 19$ & $2(9.1)$ & $2(18.2)$ & $0(0.00)$ \\
$20-29$ & $5(22.7)$ & $1(9.0)$ & $4(36.4)$ \\
$30-39$ & $4(18.2)$ & $2(18.2)$ & $2(18.2)$ \\
$40-49$ & $6(27.3)$ & $3(27.3)$ & $3(27.3)$ \\
$50-59$ & $3(13.6)$ & $2(18.2)$ & $1(9.0)$ \\
$\geq 60$ & $2(9.1)$ & $1(9.0)$ & $1(9.0)$ \\
Total & $22(100.0)$ & $11(100.0)$ & $11(100.0)$ \\
\hline
\end{tabular}


Table 2. Clinical features and type of surgical specimens from which MTCs were diagnosed (1994-2013).

\begin{tabular}{llll}
\hline & $\begin{array}{l}\text { Whole } \\
\text { group }(\mathbf{n} / \%)\end{array}$ & $\begin{array}{l}\text { Males } \\
(\mathbf{n} / \%)\end{array}$ & $\begin{array}{l}\text { Females } \\
(\mathbf{n} / \%)\end{array}$ \\
\hline Symptoms & & \\
\hline Diffuse gland enlargement & $10(45.5)$ & $4(36.4)$ & $6(54.5)$ \\
Left lobe enlargement & $7(31.8)$ & $4(36.4)$ & $3(27.3)$ \\
Right lobe enlargement & $4(18.2)$ & $2(18.2)$ & $2(18.2)$ \\
Cervical lymphadenopathy & $1(4.5)$ & $1(9.0)$ & $0(0.0)$ \\
Total & $22(100.0)$ & $11(100.0)$ & $11(100.0)$ \\
\hline Duration of symptoms at presentation $($ years $)$ & \\
\hline 1 & $5(31.2)$ & $3(37.5)$ & $2(25.0)$ \\
2 & $4(25.0)$ & $4(50.0)$ & $0(0.0)$ \\
3 & $3(18.8)$ & $0(0.0)$ & $3(37.5)$ \\
4 & $1(6.2)$ & $1(12.5)$ & $0(0.0)$ \\
$\geq 5$ & $3(18.8)$ & $0(0.0)$ & $3(37.5)$ \\
Total & $16(100.0)$ & $8(100.0)$ & $8(100.0)$ \\
\hline Type of surgical specimens & & \\
\hline Total thyroidectomy & $6(27.3)$ & $2(18.2)$ & $4(36.4)$ \\
Neck dissection & $2(9.0)$ & $0(0.0)$ & $2(18.2)$ \\
Lobectomy & $11(50.0)$ & $6(54.5)$ & $5(45.4)$ \\
Incision biopsy & $3(13.7)$ & $3(27.3)$ & $0(0.0)$ \\
\hline \multicolumn{4}{l}{}
\end{tabular}

had neck dissection (18.2\%).

\section{Invasion of surrounding structures}

At the time of histological diagnosis 5 (22.7\%) patients had nodal involvement, 3(13.6\%) with vascular invasions and one with invasion of the neck muscles (4.5\%) at the time of histological diagnosis.

\section{Discussion}

In our institution patients diagnosed with medullary thyroid cancer (MTC) were not categorised into sporadic and familial cases [3-7] and thus not grouped as such in this review. We found that MTC was the third common thyroid malignancy. This is similar to previous studies in Ghana [8] and Nigeria [9]. The current rank of MTC however differs from other studies in Africa that found it to be the fourth common type of thyroid malignancy $[10,11]$. The relative proportion of MTC in this current study was $10.0 \%$. This rate is comparable to those reported by Sippel et al., [12] and Williams et al., [13], but much higher than the $1-2 \%$ and $4.0 \%$ reported by Well et al., study [14] and Hundahl et al., [15] respectively.

MTC was commonly diagnosed in younger patients with a mean age of 38.4 years. Although the study did not categorise patients into hereditary and sporadic forms of MTC, this value is closer to the mean age of 38.0 years previously reported by Kebebew et al., [16] who did not group their patients into the two forms. Furthermore, the current mean age of patients with MTCs lies between the mean age of 35.0 years for familial variant [6] and 46.7 years for patients with sporadic variant $[13,17]$.

There were equal numbers of males and females diagnosed with MTC in the present study. This finding differs from those reported by Saral et al., [17] who found the disease to be twice as common in men as in women. This finding is also different from the studies of Sipple et al., [12] and Williams et al., [13] that found female predominance, but similar to the study of Grubbs et al., [18] that found no difference in incidence

Table 3. Comparing the clinical presentation of MTC between males and females using Chi-Square Test.

\begin{tabular}{|c|c|c|c|c|c|c|}
\hline & \multicolumn{6}{|c|}{ Age groups ( Years) cross tabulation } \\
\hline & $\leq 29$ & $30-39$ & $40-49$ & $\geq 50$ & Total & P-value \\
\hline Sex: Female & 4 & 2 & 3 & 2 & 11 & 0.530 \\
\hline Male & 3 & 2 & 3 & 3 & 11 & \\
\hline \multirow[t]{3}{*}{ Total } & 7 & 4 & 6 & 5 & 22 & -- \\
\hline & \multicolumn{6}{|c|}{ Part of thyroid involved cross tabulation } \\
\hline & Whole & Left lobe & Right lobe & Lymph node & Total & P-value \\
\hline Sex:Female & 6 & 4 & 1 & 0 & 11 & 0.630 \\
\hline \multirow[t]{4}{*}{ Male } & 4 & 4 & 2 & 1 & 11 & \\
\hline & 10 & 8 & 3 & 1 & 22 & -- \\
\hline & \multicolumn{6}{|c|}{ Type of surgical specimens cross tabulation } \\
\hline & Neck dissection & Excision/ incision biopsy & Thyroidectomy & Lobectomy & Total & P-value \\
\hline Sex: Female & 2 & 0 & 4 & 5 & 11 & 0.169 \\
\hline Male & 0 & 5 & 2 & 4 & 11 & \\
\hline \multirow[t]{3}{*}{ Total } & 2 & 5 & 6 & 9 & 22 & -- \\
\hline & \multicolumn{6}{|c|}{ Duration of symptoms at presentation cross tabulation } \\
\hline & 1 & 2 & 3 & $\geq 4$ & Total & P-value \\
\hline Sex: Female & 2 & 0 & 3 & 3 & 8 & 0.111 \\
\hline Male & 3 & 4 & 0 & 1 & 8 & \\
\hline Total & 5 & 4 & 3 & 4 & 16 & -- \\
\hline
\end{tabular}


Edmund Muonir Der, Pathology Discovery 2017,

bet-ween males and females.

The majority of patients diagnosed with MTC presented with thyroid gland enlargement, as found in previous publications [17-20]. In this current study, $27.3 \%$ of the patients with MTC had nodal involvement at histological diagnosis. This rate is lower than the 35\%-50\% reported in the study by Sipple [12] and $80.0 \%$ in the study of Moley et al., [20]. There is no apparent reason for the low extra nodal involvement by MTC in this study. It may however be due to the fact that only $27.2 \%$ and $9.0 \%$ of the patient with MTC had total thyroidectomy andneck dissection respectively.

Studies published in the last decade found MTC to have relatively good 5-year and 10-year survival rates [21-23]. In the current study approximately $77.2 \%$ of patients diagnosed with MTCs were younger than 50 years of age and a significant number (59.1\%) were organ confined. Although $22.7 \%$ of the patients had nodal involvement it has been found that the presence of cervical lymph node metastases does not affect the survival adversely $[\mathbf{2 2}, \mathbf{2 3}]$. Direct invasion of the surrounding neck structures by MTC has been shown to be a bad prognostic factor [23]. But the current study found neck muscle invasion in just one case. In view of the younger age at diagnosis, organ confined cancer and the lack of invasion of surrounding neck structures, the author opines that the outcome of the disease in these patients will be favourable as suggested in the literature [24-26].

\section{Conclusion}

Medullary thyroid cancer was found to be the third common thyroid malignancy in the current studywith no significant sex differences in the clinical presentation. Patients were relatively younger and presented late with large anterior neck swelling. Majority of the patients had organ confined disease at diagnosis.

\section{Competing interests}

The author declares that he has no competing interests.

\section{Acknowledgements and funding}

The author thanks the staff of the Department of Pathology whose work generated the data. Much thanks to Prof Francis Abantanga, the Dean of the School of Medicine and Health Sciences, of the University for Development Studies, Tamale for reading through the final manuscript and offering his comments and corrections. The author did not receive any funding for this work.

Publication history

Senior Editor: Jasvir S. Khurana, Temple University, USA.

Received: 04-Jan-2017 Final Revised: 13-Feb-2017

Accepted: 28-Feb-2017 Published: 09-Mar-2017

\section{References}

1. Block MA, Jackson CE, Greenawald KA, Yott JB and Tashjian AH, Jr. Clinical characteristics distinguishing hereditary from sporadic medullary thyroid carcinoma. Treatment implications. Arch Surg. 1980; 115:142-8. | Article | PubMed
2. Hazard JB, Hawk WA and Crile G, Jr. Medullary (solid) carcinoma of the thyroid; a clinicopathologic entity. J Clin Endocrinol Metab. 1959; 19:152-61. | Article | PubMed

3. Galofre JC, Yazbeck CF and Shaw S. Multifocality at diagnosis is predictive of worse prognosis in sporadic medullary thyroid cancer. In: International Congress of Endocrinology. Rio de Janeiro. 2008.

4. Pelizzo MR, Boschin IM, Bernante P, Toniato A, Piotto A, Pagetta C, Nibale O, Rampin L, Muzzio PC and Rubello D. Natural history, diagnosis, treatment and outcome of medullary thyroid cancer: 37 years experience on 157 patients. Eur J Surg Oncol. 2007; 33:493-7. | Article | PubMed

5. Roman S, Lin R and Sosa JA. Prognosis of medullary thyroid carcinoma: demographic, clinical, and pathologic predictors of survival in 1252 cases. Cancer. 2006; 107:2134-42. | Article | PubMed

6. Machens A, Schneyer U, Holzhausen HJ and Dralle H. Prospects of remission in medullary thyroid carcinoma according to basal calcitonin level. J Clin Endocrinol Metab. 2005; 90:2029-34. I Article I PubMed

7. Steiner AL, Goodman AD and Powers SR. Study of a kindred with pheochromocytoma, medullary thyroid carcinoma, hyperparathyroidism and Cushing's disease: multiple endocrine neoplasia, type 2. Medicine (Baltimore). 1968; 47:371-409. I PubMed

8. Der EM, Quayson SE, Clegg-Lamptey JN, Wiredu EK, Ephraim RKD and Gyasi RK. Thyroid Disorders in Accra, Ghana: A Retrospective Histopathological Study at the Korle-Bu Teaching Hospital. Journal of Medical and Biomedical Sciences. 2013; 21: 1-7. | Article

9. Thomas JO and Ogunbiyi JO. Thyroid cancers in Ibadan, Nigeria. East Afr Med J. 1995; 72:231-3. | PubMed

10. Ogbera $A O$ and Kuku SF. Epidemiology of thyroid diseases in Africa. Indian J Endocrinol Metab. 2011; 15:S82-8. | Article | PubMed Abstract | PubMed FullText

11. Mulaudzi TV, Ramdial PK, Madiba TE and Callaghan RA. Thyroid carcinoma at King Edward VIII Hospital, Durban, South Africa. East Afr Med J. 2001; 78:242-5. | PubMed

12. Sippel RS, Kunnimalaiyaan $M$ and Chen $H$. Current management of medullary thyroid cancer. Oncologist. 2008; 13:539-47. | Article | PubMed

13. Williams ED, Brown CL and Doniach I. Pathological and clinical findings in a series of 67 cases of medullary carcinoma of the thyroid. J Clin Pathol. 1966; 19:103-13. | Article I PubMed Abstract I PubMed FullText

14. Wells SA, Jr., Asa SL, Dralle H, Elisei R, Evans DB, Gagel RF, Lee N, Machens A, Moley JF, Pacini F, Raue F, Frank-Raue K, Robinson B, Rosenthal MS, Santoro M, Schlumberger M, Shah M and Waguespack SG. Revised American Thyroid Association guidelines for the management of medullary thyroid carcinoma. Thyroid. 2015; 25:567-610. | Article | PubMed Abstract | PubMed FullText

15. HundahI SA, Fleming ID, Fremgen AM and Menck HR. A National Cancer Data Base report on 53,856 cases of thyroid carcinoma treated in the U.S., 1985-1995 [see commetns]. Cancer. 1998; 83:2638-48. I PubMed

16. Kebebew E, Ituarte $\mathrm{PH}$, Siperstein AE, Duh QY and Clark OH. Medullary thyroid carcinoma: clinical characteristics, treatment, prognostic factors, and a comparison of staging systems. Cancer. 2000; 88:1139-48. I PubMed

17. Desai SS, Sarkar S and Borges AM. A study of histopathological features of medullary carcinoma of the thyroid: cases from a single institute in India. Indian J Cancer. 2005; 42:25-9. | Article | PubMed

18. Grubbs EG, Rich TA, Li G, Sturgis EM, Younes MN, Myers JN, EdeikenMonroe B, Fornage BD, Monroe DP, Staerkel GA, Williams MD, Waguespack SG, Hu MI and Cote $\mathrm{G}$ et al. Recent advances in thyroid cancer. Curr Prob/ Surg. 2008; 45:156-250. | Article | PubMed

19. Scollo C, Baudin E, Travagli JP, Caillou B, Bellon N, Leboulleux S and Schlumberger M. Rationale for central and bilateral lymph node dissection in sporadic and hereditary medullary thyroid cancer. J Clin Endocrinol Metab. 2003; 88:2070-5. | Article | PubMed

20. Moley JF and DeBenedetti MK. Patterns of nodal metastases in palpable medullary thyroid carcinoma: recommendations for extent of node dissection. Ann Surg. 1999; 229:880-7. | Article | PubMed Abstract | PubMed FullText 
Edmund Muonir Der, Pathology Discovery 2017,

http://www.hoajonline.com/journals/pdf/2052-7896-5-1.pdf

21. Kakudo K, Carney JA and Sizemore GW. Medullary carcinoma of thyroid. Biologic behavior of the sporadic and familial neoplasm. Cancer. 1985; 55:2818-21. | Article | PubMed

22. Scheuba C, Kaserer K, Bieglmayer C, Asari R, Riss P, Drosten R and Niederle B. Medullary thyroid microcarcinoma recommendations for treatment - a single-center experience. Surgery. 2007; 142:1003-10. | Article | PubMed

23. Saad MF, Ordonez NG, Rashid RK, Guido JJ, Hill CS, Jr., Hickey RC and Samaan NA. Medullary carcinoma of the thyroid. A study of the clinical features and prognostic factors in 161 patients. Medicine (Baltimore). 1984; 63:319-42. | PubMed

24. Grozinsky-Glasberg S, Benbassat CA, Tsvetov G, Feinmesser R, Peretz $\mathrm{H}$, Shimon I and Lapidot M. Medullary thyroid cancer: a retrospective analysis of a cohort treated at a single tertiary care center between 1970 and 2005. Thyroid. 2007; 17:549-56. | Article | PubMed

25. Ogilvie JB and Kebebew E. Indication and timing of thyroid surgery for patients with hereditary medullary thyroid cancer syndromes. J Natl Compr Canc Netw. 2006; 4:139-47. | Article | PubMed

26. Roman S, Lin R and Sosa JA. Prognosis of medullary thyroid carcinoma: demographic, clinical, and pathologic predictors of survival in 1252 cases. Cancer. 2006; 107:2134-42. | Article | PubMed

\section{Citation:}

Der EM. Pathological and clinical findings in a series of 22 cases of medullary carcinoma of the thyroidat the korle-bu teaching hospital (1994-2013). Pathol Discov. 2017; 5:1. http://dx.doi.org/10.7243/2052-7896-5-1 